
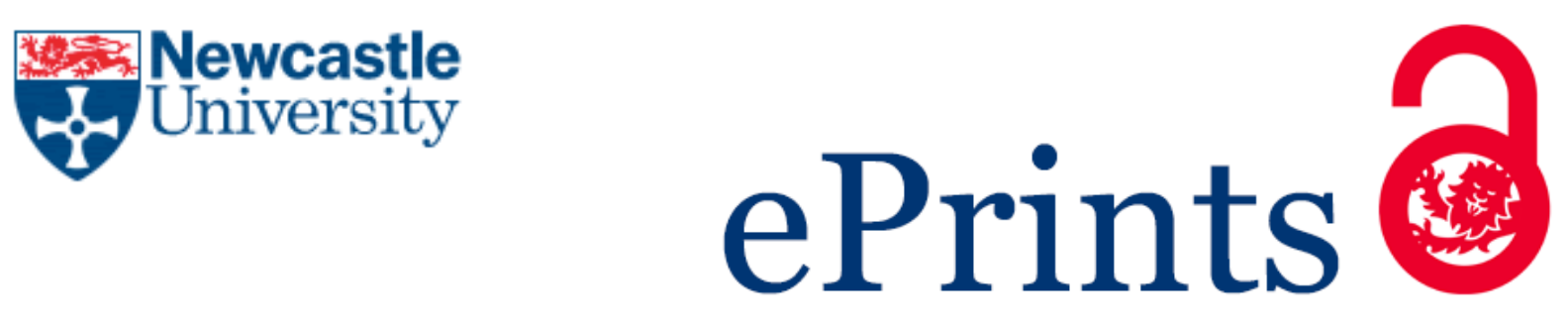

Kendon EJ, Ban N, Roberts NM, Fowler HJ, Roberts MJ, Chan SC, Evans JP, Fosser G, Wilkinson JM.

Do convection-permitting regional climate models improve projections of future precipitation change?.

Bulletin of the American Meteorological Society 2017, 98(1), 79-93.

\title{
Copyright:
}

C2017 American Meteorological Society. This article may be downloaded for personal use only. Any other use requires prior permission of the author and the American Meteorological Society.

DOI link to article:

http://dx.doi.org/10.1175/BAMS-D-15-0004.1

Date deposited:

$20 / 06 / 2017$

Embargo release date:

23 July 2017 


\title{
DO CONVECTION-PERMITTING REGIONAL CLIMATE MODELS IMPROVE PROJECTIONS OF FUTURE PRECIPITATION CHANGE?
}

\author{
Elizabeth J. Kendon, Nikolina Ban, Nigel M. Roberts, Hayley J. Fowler, Malcolm J. Roberts, \\ Steven C. Chan, Jason P. Evans, Giorgia Fosser, and Jonathan M. Wilkinson
}

Climate change experiments at very high (kilometer scale) resolution are now available that provide potential added value to future projections for convective precipitation, wind gusts, hail, fog, and lightning.

A recent step change in climate modeling capability has allowed a number of international groups to carry out very high resolution (kilometer scale) regional climate model experiments. This provides an opportunity to review the extent to which currently available regional climate projections from coarser-resolution models are reliable. In this paper, we examine whether very high resolution models provide new or different precipitation projections from traditional coarser-resolution climate models and, equally importantly, where results are robust across resolutions. Our aim is to provide guidance on the extent to which current regional and national climate scenarios, all of which are based on coarseresolution model output, provide reliable information with which to inform policy decisions and impacts assessments, and which information must be updated using very high resolution projections.

Global climate models (GCMs) are our primary tool for understanding how climate may change in the future with increasing greenhouse gases. These typically have coarse resolutions with grid spacings of $60-300 \mathrm{~km}$. To provide regional detail, higher-resolution regional climate models (RCMs; $12-50-\mathrm{km}$ grid spacing) are often used, which only span a limited area. Since different models typically represent key small-scale processes in the climate system in slightly different ways, an ensemble of multiple GCMs and RCMs is often used to give an estimate of modeling uncertainty in regional climate projections. Recent examples of coordinated regional climate modeling experiments are the EnsembleBased Predictions of Climate Changes and Their Impacts (ENSEMBLES; Hewitt and Griggs 2004), North American Regional Climate Change Assessment Program (NARCCAP; Mearns et al. 2009), New South Wales (NSW)/Australian Capital Territory (ACT) Regional Climate Modelling (NARCliM; Evans et al. 2014), and Coordinated Regional Climate Downscaling Experiment (CORDEX; Giorgi et al. 2009) projects, which use a multimodel approach to downscale to $12-50-\mathrm{km}$ resolution. An alternative approach was taken by the U.K. climate projections (UKCP09; Murphy et al. 2009) that used a perturbed physics ensemble, whereby uncertain model parameters were varied within a single GCM to give 
probabilistic projections that sampled both parameter uncertainty and internal climate variability. Information from a multimodel ensemble was also incorporated, as well as information from observations to weight different model versions depending on their ability to accurately simulate the historical climate. In UKCP09, the GCM simulations were run at a resolution of $300 \mathrm{~km}$ and were then downscaled using an ensemble of RCMs at $25-\mathrm{km}$ resolution.

Although these ensemble-based approaches give some estimate of modeling uncertainty, they do not reveal uncertainties that arise from limitations inherent in all models at those resolutions. At typical climate model resolutions $(10-100 \mathrm{~km})$ many important processes (such as those in clouds) occur on spatial scales too small to be resolved explicitly on the model grid and are therefore represented using parameterizations. A good example of this is convection parameterization, which aims to describe the average properties of convection over a model grid box but leads to deficiencies in the diurnal cycle of convection, precipitation occurrence, and extremes (Dai 2006; Hohenegger et al. 2008; Stephens et al. 2010).

The first climate change experiments at very high resolution $(<5-\mathrm{km}$ grid spacing) have recently been completed for the United Kingdom (Kendon et al. 2014); the Alpine region (Ban et al. 2015); central Germany (Tolle et al. 2014); southwestern Germany (Fosser et al. 2016); Sydney, Australia (Argueso et al. 2014); the Colorado headwaters (Rasmussen et al. 2014); and the western United States (Pan et al. 2011). At these resolutions, the deep convective parameterization scheme can be switched off, with the use of shallow

AfFiliations: Kendon AND RoberTs-Met Office Hadley Centre, Exeter, United Kingdom; BAN-Institute for Atmospheric and Climate Science, ETH Zurich, Zurich, Switzerland; ROBERTSMetOffice@Reading, Reading, United Kingdom; FowLER AND CHAN-School of Civil Engineering and Geosciences, Newcastle University, Newcastle upon Tyne, United Kingdom; EvansUniversity of New South Wales, Sydney, New South Wales, Australia; FoSSER*-CNRM-GAME, CNRS, and Météo-France, Toulouse, France; WILKINSON-Met Office, Exeter, United Kingdom *CURRENT AfFILIATION: Fosser-Met Office Hadley Centre, Exeter, United Kingdom CORRESPONDING AUTHOR E-MAIL: Elizabeth J. Kendon, elizabeth.kendon@metoffice.gov.uk

The abstract for this article can be found in this issue, following the table of contents.

DOI:10.II75/BAMS-D-15-0004.I

A supplement to this article is available online (10.1175/BAMS-D-15-0004.2)

In final form 29 June 2016

(2)2017 American Meteorological Society convective parameterization varying between studies. Deep convection schemes are not designed to operate in kilometer-scale models, and many of the assumptions of these schemes (e.g., that the cloud coverage is small compared to the grid square) are violated at these resolutions. Shallow plumes typically have smaller horizontal length scales and without some kind of parameterization there is a missing process (small cumulus clouds are too small to be explicitly represented on the grid), but the use of shallow convective parameterization is only appropriate if the scheme has been designed to operate at kilometer scale. At this scale, the model is termed "convection permitting" because larger convective storms are "permitted" but convective plumes and smaller showers are still not resolved. Such convection-permitting models are commonly used in short-range weather forecasting, where they have been shown to give a much more realistic representation of convection and can be used to forecast the possibility of localized high-impact rainfall not captured at coarser resolutions (Done et al. 2004; Lean et al. 2008; Weisman et al. 2008; Weusthoff et al. 2010; Schwartz 2014). However, because of their high computational cost, they have not commonly been applied at climate time scales. Convection-permitting models do not necessarily better represent daily mean precipitation (Chan et al. 2013), but they have significantly better subdaily rainfall characteristics with improved representation of the diurnal cycle of convection (Ban et al. 2014), the spatial structure of rainfall and its duration-intensity characteristics (Kendon et al. 2012), and the intensity of hourly precipitation extremes (Chan et al. 2014a; Ban et al. 2014; Fosser et al. 2015), which are typically poorly represented in climate models. Prein et al. (2015) provide an excellent review of the added value of convection-permitting climate modeling, showing added value emerging when and where deep convection is dominant and in regions of strong spatial heterogeneities (mountains and urban areas). Although convection-permitting models still contain errors, for example, smaller showers are not properly resolved, leading to a tendency for heavy rainfall to be too intense (Kendon et al. 2012; Fosser et al.2015), they provide a step change in our ability to represent convection and an opportunity to examine the importance of representing local storms for future climate projections.

In this paper, we bring together results from climate change experiments performed at $1.5-\mathrm{km}$ resolution over the southern United Kingdom (Kendon et al. 2014) and $2.2 \mathrm{~km}$ over the Alpine region (Ban et al. 2015) to explore commonalities, and we also refer to findings from numerical weather prediction (NWP) 
and convection-permitting climate studies recently completed for other regions. The U.K. simulations span the southern United Kingdom and are driven by a 12-km RCM that spans Europe and is in turn driven by a $60-\mathrm{km}$ GCM, with all models being configurations of the Met Office Unified Model (Walters et al. 2011). The Alps simulations span the greater Alpine region and are driven by a $12-\mathrm{km}$ European RCM, which is in turn driven by a T63 spectral $(\sim 200 \mathrm{~km})$ resolution GCM. In this case the RCM is the Consortium for Small-Scale Modelling Climate Local Model (COSMOCLM), while the GCM is the Max Planck Institute Earth System Model, low resolution (MPI-ESM-LR; Stevens et al. 2013). In both cases the simulations are for two $\sim 10$-yr periods, one corresponding to the present day and the other to the end of the century under representative concentration pathway 8.5 (RCP8.5; the exact period and run length varies between experiments; see online supplemental material for details: http://dx.doi .org/ I 0.I I75/BAMS-D-15-0004.2). Given in each case we are restricted to only one model realization, we are unable to assess uncertainty in the climate change signal. However, where commonalities in the effect of resolution are identified across different regions and different climate models, we have greater confidence in the result.

This paper complements the review of Prein et al. (2015), which mostly focused on the added value of convection-permitting simulations for present-day climate variability, by assessing whether such very high resolution models are needed for reliable future projections. We focus on rainfall projections, since these are expected to be most sensitive to model resolution and the explicit representation of convection. We also consider implications for other climate variables, including wind, hail, fog, lightning, and soil moisture.

TO WHAT EXTENT DO PRECIPITATION PROJECTIONS AGREE BETWEEN COARSEAND HIGH-RESOLUTION RCMS? Coarseresolution $R C M s$ are likely to provide robust projections of changes in seasonal mean rainfall, providing that large-scale changes from the GCM are reliable. We find that projected changes in seasonal mean rainfall are in close agreement between high-resolution (convection permitting) and coarser-resolution (convection parameterized) regional climate models, driven by the same large-scale conditions. For example, Figs. 1 and 2 show projected changes to winter and summer rainfall over the southern United Kingdom for a 1.5- and 12-km RCM [described in Kendon et al. (2014)]. Similar agreement in projected changes in summer mean precipitation is found in Ban et al. (2015) for 2.2- and 12-km RCMs over the Alps and in Fosser et al. (2016) for 2.8- and 7-km models over southwestern Germany. For summer, this agreement is probably because the convection scheme is able to (and indeed designed to) simulate time-averaged precipitation, even if the diurnal cycle is incorrect (too strong midday peak) and short-time scale intensity is too weak, and for winter because mean rainfall is dominated by largerscale dynamical rainbands that are well captured at $12 \mathrm{~km}$. We note that Rasmussen et al. (2014) found reduced biases in the representation of mean summer rainfall in a convection-permitting model over the Colorado headwaters, which may impact future projected changes, but the improvement here is likely to be linked specifically to the improved representation of complex topography at high resolution.

Changes in daily and hourly rainfall are, however, more important than changes in seasonal averages for many climate impacts. In particular, changes in the intensity and duration of rainfall are crucial for understanding future flood risk, and changes in the occurrence of rainfall are important for water resource planning and agriculture. Hence, we now turn our attention to examine whether these aspects of rainfall change are robust from coarser to higher model resolution.

Changes in rainfall occurrence are largely consistent between convection-permitting and coarser resolutions in summer and winter. We find that changes in rainfall occurrence are largely consistent between the convection-permitting and parent $12-\mathrm{km} \mathrm{RCM}$, in winter and summer, for both the U.K. and Alps simulations (Figs. 3,4 ), with large decreases in rainfall occurrence in summer at both resolutions. For the United Kingdom, this is despite present-day biases being quite different between the two different resolution models, with the $12-\mathrm{km}$ RCM tending to have too many wet hours and wet days, while the $1.5 \mathrm{-km}$ RCM has too few, especially in summer. Fosser et al. (2016) also show a similar decrease in summer rainfall occurrence in 2.8and 7-km models, despite quite different biases across model resolution for the present day. Large RCM biases for the Alps simulations are largely inherited from the driving GCM, with biases for European Centre for Medium-Range Weather Forecasts (ECMWF) interim reanalysis (ERA-Interim; Dee et al. 2011) driven simulations being much smaller (see Figs. ES1 and ES2 in the online supplemental material). Known problems with radar over mountainous regions, and sampling errors associated with gauge observations, may also contribute to the apparently larger biases over the Alps compared to the United Kingdom. The tendency for too much low-intensity precipitation in the Alps 
(a) Radar, djf
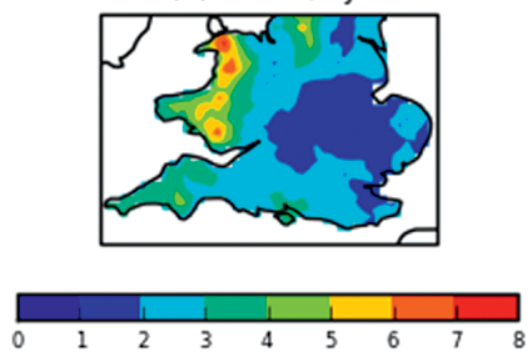

(b) $1.5 \mathrm{~km}$ bias, djf
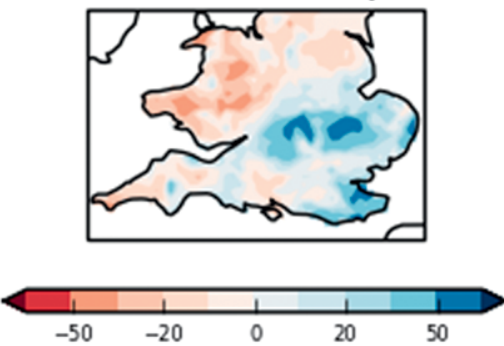

(d) $12 \mathrm{~km}$ bias, djf
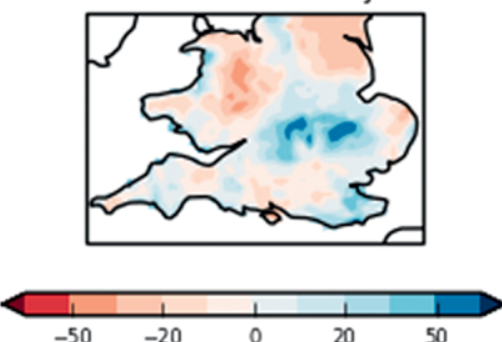

(c) $1.5 \mathrm{~km}$ future change, $\mathrm{djf}$
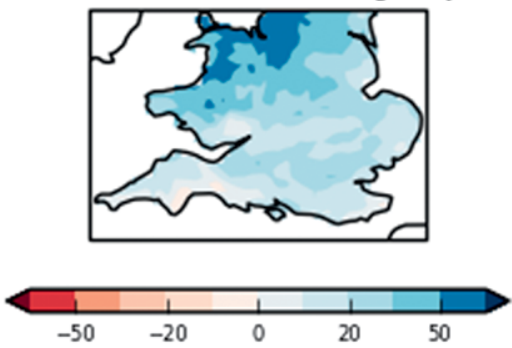

(e) $12 \mathrm{~km}$ future change, djf
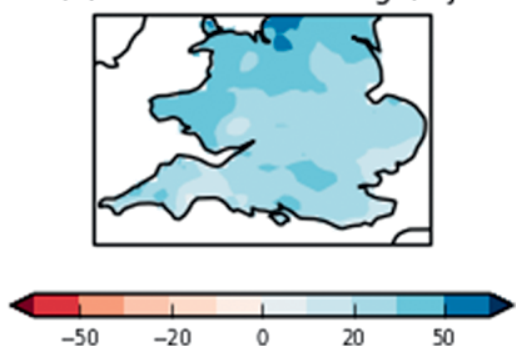

FIG. I. Seasonal mean rainfall $\left(\mathrm{mm} \mathrm{day}^{-1}\right)$ over the southern United Kingdom for winter [Dec-Feb (DJF)] in the (a) radar, and (b),(d) model-radar differences (\%) and (c),(e) future changes (\%) for the $1.5-$ and $12-\mathrm{km}$ RCMs. The RCM simulations are for I3-yr present-day (1996-2009) and I3-yr future (2100, under RCP8.5 scenario) periods. Radar data are for the period 2003-12. Results are only shown over U.K. land points.

simulations in winter is most apparent on the hourly time scale, since when averaging over longer periods, multiple hourly occurrences still give the same daily count as a single occurrence on that day. We note that although the differences between the Alps and U.K. results are probably in part because of the driving model differences and/or verification data, there are also likely to be some differences that come from the contrast in topography and nature of the rainfall between the two regions (Alps drier in winter and more convective in summer in comparison to the United Kingdom). We expect high resolution to be beneficial for both frontal and convective rain over regions of steep orography, with the occurrence and spatial patterns of rainfall better captured over mountainous regions (Prein et al. 2015), whereas in flatter regions frontal rain (especially in winter) is sufficiently well captured at coarser resolutions. In general, the improved representation of orography at high resolution is expected to impact

rainfall on longer temporal scales, with model biases focused on the hourly time scale expected to be more related to the representation of convection.

Chan et al. (2014b) show that over the United Kingdom the large-scale conditions from the driving GCM control whether precipitation is triggered or not, but how long the precipitation lasts once triggered is sensitive to the RCM model physics (and is different between convection-permitting and convection-parameterized models). The former (i.e., changes in triggering) dominates the future decrease in summer rainfall occurrence, whereas the latter (i.e., how long it lasts) leads to the resolution dependence of present-day biases. Thus, coarser-resolution RCMs are likely to be sufficient for projecting changes in the occurrence of rainfall where this is dominated by changes to the triggering of events. Since dry spell length is determined by the sequence of rainfall events (synonymous with triggering), we expect changes in dry spell length to also be robustly captured at coarser resolution. We note that this result may not extend to those tropical regions where large-scale forcing is less dominant in triggering events, although it may apply in some tropical areas where the large-scale matters more (e.g., African easterly waves, Indian monsoon).

Changes in rainfall intensity are robust across model resolution in winter but show significant differences in summer. We find good agreement between convectionpermitting and 12-km RCM results, for both the U.K. and Alps simulations, for change to winter precipitation intensities (Fig. 5). This is despite resolutiondependent model biases for the present day in some cases. The agreement in changes across resolution can be explained by the fact that changes in intensity over Europe in winter come predominantly from frontal rain from midlatitude weather systems with 
greater moisture availability (Kendon et al. 2014)-a process well captured by coarse-resolution climate models. In summer, by contrast, convection-permitting models show significant increases in rainfall intensity over the southern United Kingdom and the Alps (Fig. 6), that are not captured by the parent $12-\mathrm{km}$ RCM, for a comparison made at the $12-\mathrm{km}$ scale (Kendon et al. 2014; Ban et al. 2015). This can be explained by the $12-\mathrm{km}$ RCM being constrained by the behavior of the convection parameterization. These increases become larger in relative terms at finer spatial and temporal scales. It is notable that the pattern of future changes across space and time scales, and across resolution, is remarkably similar between the southern U.K. and the Alps simulations. The convection-permitting model tends to have reduced biases in summer, although in the case of the Alps simulations, there are large RCM biases inherited from the driving GCM (see Figs. ES3 and ES4 in the online supplemental material). Fosser et al. (2016) found contrasting results with similar increases in intensity for $2.8-\mathrm{km}$ convection-permitting and $7-\mathrm{km}$ convection-parameterized models over southwestern Germany, although with different spatial patterns. The agreement across resolution in this latter study may be due to the relatively high resolution of the convection-parameterized model [ $7 \mathrm{~km}$ compared to $12 \mathrm{~km}$ in Kendon et al. (2014) and Ban et al. (2015)].

We note that Ban et al. (2015) found greater consistency between the 2.2- and 12-km RCMs for a metric of heavy rainfall (specifically, percentiles of all values instead of only wet values, and hence a measure of rainfall intensity and frequency combined). However, further analysis for the United Kingdom reveals such agreement does not extend across a range of percentiles. Thus, the finding that changes in summertime rainfall intensity are resolution dependent does not appear to simply be an artifact of the chosen metric.
Convection-permitting resolution is needed to capture changes in the duration of summertime rainfall. Projected changes in the duration of summertime rain are quite different between convection-permitting and coarserresolution models over the southern United Kingdom (Kendon et al. 2014, and figures therein). In the 12-km RCM, precipitation tends to be too low intensity and too long duration, with these biases largely eliminated in the $1.5-\mathrm{km}$ model because of the better representation of convective rain (Kendon et al. 2012). Fosser et al. (2016) found contrasting results with similar changes in the intensity-duration characteristics of rainfall in 2.8- and 7-km models over southwestern Germany. This better agreement may be due to the relatively high resolution $(7 \mathrm{~km})$ of the convectionparameterized model or the small size of the $2.8-\mathrm{km}$ model domain, which may limit the RCM's ability to generate its own small-scale features.

Changes in daily and hourly rainfall extremes are not robust across model resolution, particularly in summer. For the United Kingdom, projected changes to extreme hourly rainfall differ markedly between 1.5- and 12-km 

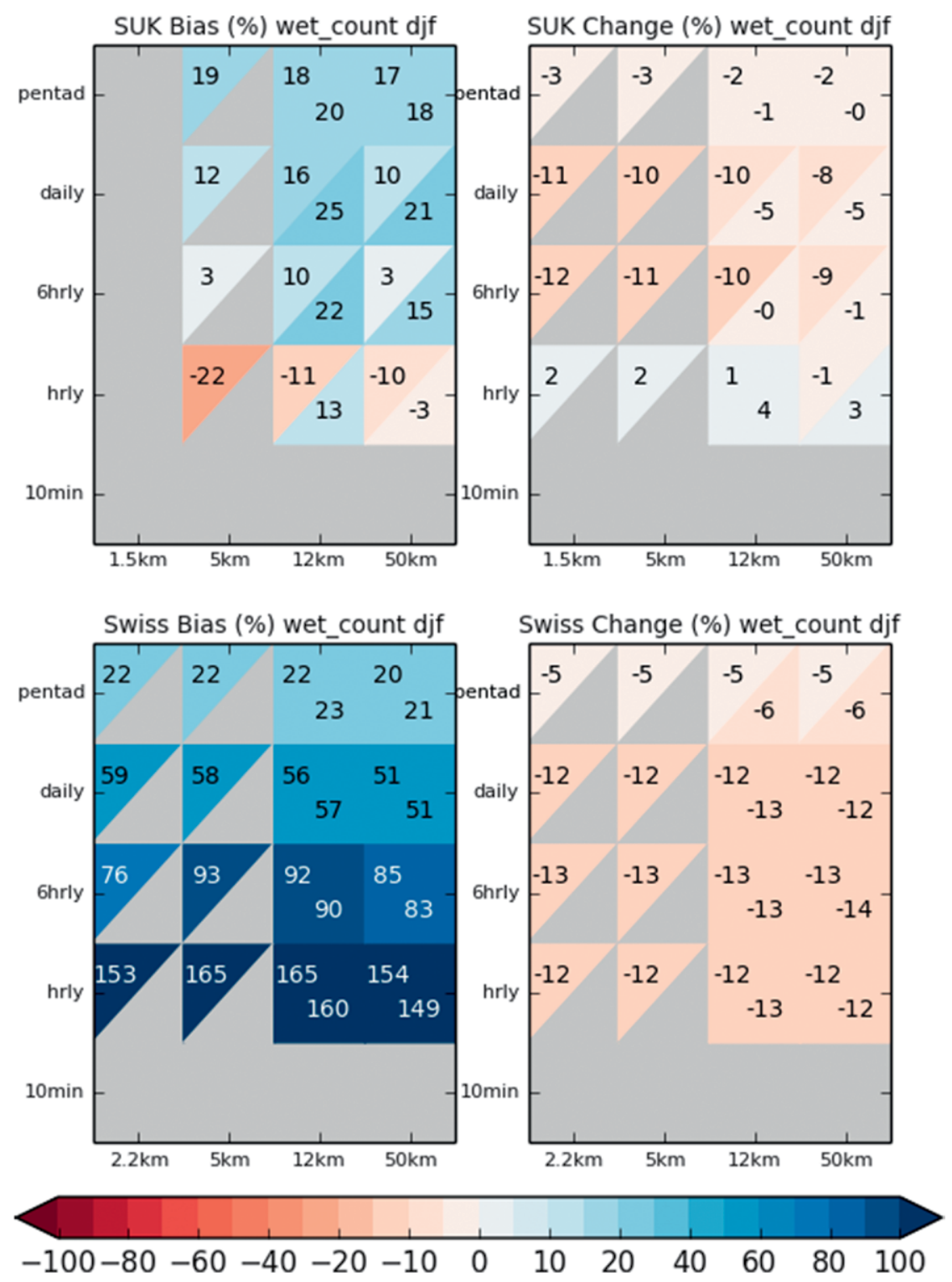

FIG. 3. (left) Biases and (right) changes (\%) in rainfall occurrence across space and time scales averaged over the (top) southern United Kingdom and (bottom) Switzerland in winter (DJF). Biases are calculated as model-observation differences, using hourly 5 - $\mathbf{k m}$ Nimrod radar data for the United Kingdom for 2003-I2 (Golding 1998) and I-km RdisaggH combined radar-gauge observations for Switzerland for 2004-10 (Wuest et al. 2010). Changes correspond to differences between decadal-length present-day and future (end of century, under RCP8.5) simulations. Results for the convection-permitting (I.5 or $2.2 \mathrm{~km}$ ) $R C M$ are shown in the upper-left triangle and for the I2-km RCM in the lowerright triangle. Gray indicates where results are not available. A threshold of $0.1 \mathrm{~mm}$ per accumulation period is used to define rainfall occurrence. the Alps are consistent with results for the United Kingdom: Ban et al. (2015) find considerable discrepancies in projected changes in extreme hourly intensities in summer between 2.2- and $12-\mathrm{km}$ resolution. In winter, there is some suggestion that projected changes in U.K. extreme daily rainfall over orography may be greater at convection-permitting resolution (Chan et al. 2014b). This may be explained by a stronger response associated with the more accurate representation of orography in the high-resolution model, which may affect daily rainfall accumulations more than 1-h accumulations. We may expect the benefit of high resolution to be different over orography, with improved representation of topography as well as improved representation of convective storms impacting on precipitation. On hourly time scales, the most intense rainfall is from convective storms rather than orographic rain, and hence on shorter time scales the improved representation of convective processes should dominate, as realized by commonalities between the Alps and U.K. results.

\section{IMPLICATIONS FOR} OTHER CLIMATE VARIABLES. In this section we consider how the improved representation of convection at the kilometer resolution in summer, to the extent that they differ in sign (Chan et al. 2014b). This discrepancy is also found for daily extremes, although to a lesser extent. Extreme events (with return periods of greater than 20 years) in the 12-km RCM are linked to single gridpoint storms or storms with unphysically large updraft regions, providing low confidence in projections. Results for scale has implications for other climate variables. In particular, we consider wind, hail, fog, lightning, and soil moisture that in turn impacts local temperature. We note that the improved representation of local topography and surface heterogeneities in convectionpermitting models will also have significant impact, for example, for projections of urban temperature 
(Trusilova et al. 2013; Argueso et al. 2014, 2015) and climate over mountainous regions (Knote et al. 2010; Rasmussen et al. 2014). However, a discussion of this is beyond the scope of the current paper, which focuses on the implications of the improved representation of the local storm dynamics.

Convection-permitting resolution is needed to capture changes in severe wind gusts. Kilometer-scale models allow a more accurate representation of local wind, in part through the better representation of topography (e.g., sea breezes and mountain effects), but also as a consequence of capturing convective storms. Modeling convective wind gusts requires a convectionpermitting model; for example, derechos are severe convective squall lines with intense winds that can only be represented at convection-permitting scales. Over the United Kingdom, such systems are rare and only likely to occur in summer. In winter, the highest winds on subdaily time scales are typically associated with cyclonic storms, and coarse-resolution models ( 12-25-km grid spacing) with appropriate gust diagnostics are able to reasonably well represent these. However, there will still be some situations when local processes dominate in the smallest mesoscale systems [e.g., embedded convection or small "sting jets" (Browning 2004)].

Convection-permitting resolution is likely to give more reliable projections of future changes in hail, but further research is needed. Hail is of particular interest, being responsible for increasingly significant economic damages to buildings, crops, cars, and other infrastructure. Two events in central and southern Germany on 27 and 28 July 2013 caused the highest insured loss from a natural hazard in Germany to date. A number of studies have shown that convection-permitting climate models are able to provide useful guidance of the occurrence of hail (Trapp et al. 2011; Gensini and Mote 2014). Mahoney et al. (2012) investigated future changes in hail in convection-permitting simulations using a case study approach and found that although more hail was generated within the cloud with storm intensification, little reached the surface because of enhanced melting. It is unclear, however, whether such high resolutions are required to provide reliable projections of future changes in hail and whether the hail produced by microphysics schemes and postprocessing algorithms is sufficiently good. In particular, coarser-resolution models may 

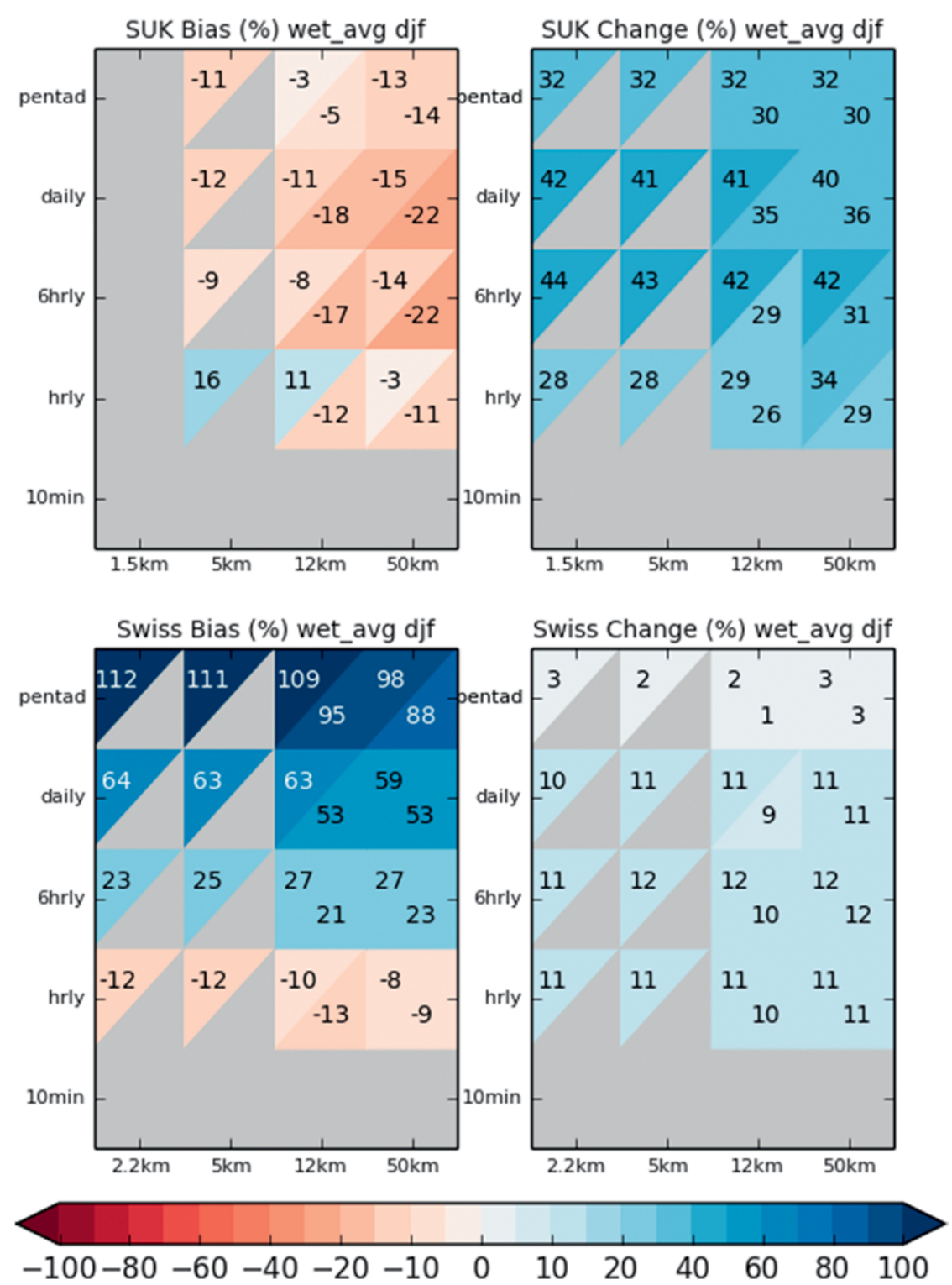

FIG. 5. (left) Biases and (right) changes (\%) in rainfall intensity across space and time scales averaged over the (top) southern United Kingdom and (bottom) Switzerland in winter (DJF). Rainfall intensity is defined as the mean of wet values (>0.1 $\mathrm{mm}$ per accumulation period). Definitions are as in Fig. 3 . with considerable uncertainties. Where changes in fog are driven by large-scale variables such as temperature and humidity, we may be able to make confident statements about large-scale changes in fog. However, on the local scale, fog depends on many different variables including topography, aerosol amounts, and local turbulent fluctuations. These processes may be better represented in a convectionpermitting model, although it is unclear whether kilometer-scale models provide more accurate future projections compared to postprocessed coarse model output. Boundary layer clouds may require resolution of turbulent eddies in some cases, which would require grid scales of "large-eddy simulation" models (tens of meters).

Convection-permitting resolution has the potential to provide more accurate lightning projections, but further research is needed. A lightning diagnostic has been developed for convectionpermitting configurations of the Met Office Unified Model, which uses a physically based link between be sufficient, if postprocessed hail diagnostics (e.g., Hand and Cappelluti 2011) are sufficiently accurate, although hail diagnosis from convection-permitting models should still give a better physical representation and is less reliant on arguably tenuous links between large-scale environmental conditions and small-scale weather extremes (Mahoney et al. 2012).

Further research is required to assess whether very high resolution is needed for projecting future changes in fog. The UKCP09 25-km models suggest the frequency of fog will be reduced in the future across the United Kingdom in many regions and seasons, but cloud properties and lightning flash rate (Wilkinson and Bornemann 2014). In particular, lightning flash rate is determined from the upward flux of graupel (McCaul et al. 2009), which in convection-parameterized models tends to be too low. An alternative commonly used by convection-parameterized models is to link the flash rate to bulk cloud properties (e.g., Price and Rind 1992). However, this statistical approach removes the link between the cloud microphysical processes. It is only in the convection-permitting model that we are able to use actual physical processes in the cloud to determine lightning. This latter approach shows good skill in forecasting the timing 
and occurrence of lightning but overpredicts its extent, although its behavior is yet to be fully determined over a long period.

Convection-permitting models may give different soil moisture conditions and feedbacks. The more realistic representation of rainfall in convection-permitting models impacts soil moisture conditions. In particular, in the present climate, the southern U.K. $1.5-\mathrm{km}$ RCM has drier soils than the $12-\mathrm{km}$ RCM because of the more sporadic nature of rainfall, which is less effective at wetting the soils. Soil moisture conditions and surface evapotranspiration may in turn have a considerable impact on local temperature changes (Tolle et al. 2014). If soils become dry enough they can limit evaporation, leading to hotter temperatures. Soil moisture-precipitation feedbacks were also found to be very different in a convection-permitting model compared to a convectionparameterized model over the Alps (Hohenegger et al. 2009). The extent to which future projected changes in soil moisture are resolution dependent is currently unexplored. However, the fact that soil moisture conditions and potentially their future change may be quite different in convectionpermitting models has important implications for changes in temperature extremes and also for climate change impacts-for example, on agriculture.

DISCUSSION. National climate change scenarios are currently available for many countries worldwide, for example, for the United Kingdom (UKCP09; Murphy et al. 2009), the Netherlands (Klein Tank et al. 2015), Switzerland (CH2011 2011), and the United States (Melillo et al. 2014). These inform adaptation planning and often feed into downstream impact assessments to inform decisions in sectors such as transport, healthcare, water resources, and flood protection. However, the quality of these national climate scenarios depends on the ability of the underlying model experiments to capture key processes, and all are based on coarse-resolution climate model simulations. In this paper we have demonstrated how new, very high resolution RCMs allow us to assess the robustness of current national climate scenarios. We conclude by providing users information on where currently available projections are reliable and, conversely, where it is necessary to use results emerging from very high resolution model experiments.

We have identified a number of aspects of midlatitude precipitation change that disagree significantly 
between convection-permitting and coarser-resolution RCMs, and for which very high resolution (kilometer scale) models are needed for accurate future projections. These include changes in 1) summertime rainfall intensity and duration, 2) hourly and daily rainfall extremes in summer, and 3) daily precipitation extremes over mountains in winter. Other aspects of precipitation change appear to be reliably captured in currently available projections from regional climate models, providing large-scale changes from the driving GCM are reliable. These include changes in 1) seasonal mean precipitation, 2) rainfall event occurrence, and 3) precipitation intensity in winter. In addition, we have identified other climate variables for which kilometerscale climate models are likely to be needed for future projections-for example, severe wind gusts-while for others, including hail, fog, and lightning, further research is required. A summary of these conclusions is presented in Fig. 7.

It is encouraging that the resolution dependence of projections for simulations over the United Kingdom and the Alps show considerable consistency. This suggests first that, with increases in model resolution, climate projections from different models may show convergence. Second, it indicates that the conclusion that the local storm dynamics (only represented in convection-permitting models) are needed for future projections of short-duration extremes is more widely applicable in other regions for convectively dominated regimes and seasons. This is supported by some observational evidence (Lenderink and van Meijgaard 2008). Although these results are for midlatitude summer precipitation, they are likely to be similar throughout the tropics, where much more precipitation arises from smaller-scale motions.

A move toward very high resolution climate modeling seems necessary for quantification of certain impacts, particularly around extremes. Reliable projections of rainfall extremes are important for understanding future flood risk and hence for informing decisions regarding urban planning, flood protection, and the design of resilient infrastructure. Surface

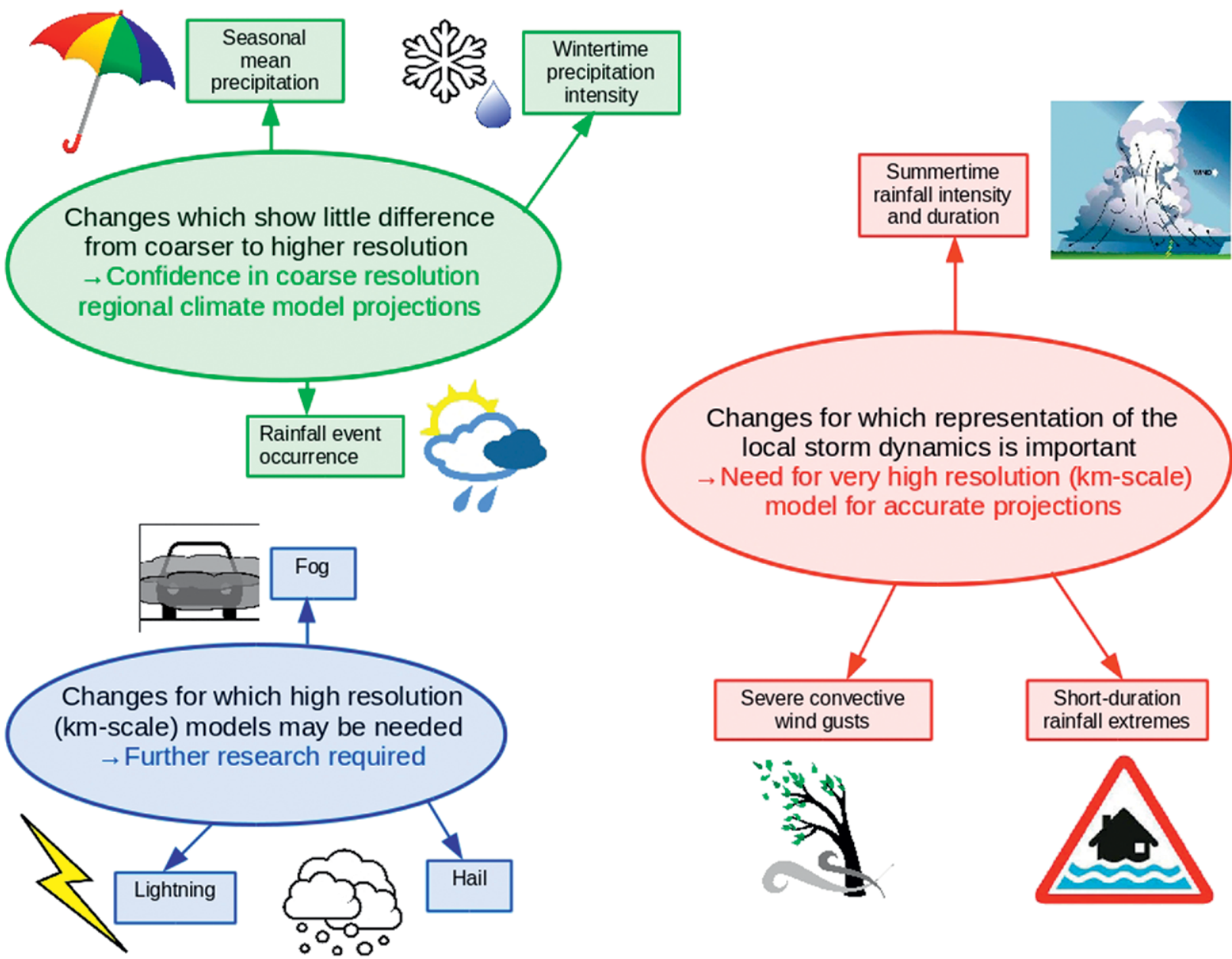

FIG. 7. Schematic summarizing where we have confidence in coarse-resolution RCM projections and where very high-resolution (kilometer scale) models are needed for accurate projections. 
water flooding and flooding from drainage networks is the predominant source of flooding in urban areas as a direct response to high-intensity, short-duration rainfall. In a recent pilot study, Dale et al. (2016) showed that estimates of rainfall intensity change from the U.K. 1.5-km climate model were higher than existing U.K. climate change allowances, leading to projections of more frequent sewer overflow spills in future. This is only one example, but it is indicative of the fact that current climate change guidance based on national climate scenarios, for example, current allowances for changes in peak rainfall intensity in the United Kingdom, may not be adequate. There is a need to revisit current guidance in the light of emerging results from very high resolution climate models. New information from these models may also help to inform a redesign of existing critical infrastructure systems. A number of recent major flood events in the United Kingdom has brought this starkly into focus.

Our findings also have implications for a number of other impact areas (Table 1):

1) Extreme winds can cause significant disruption to electricity infrastructure and transportation, and an understanding of future wind risk will inform prioritization of adaptation investments. Kilometer-scale models are needed to give improved projections of future change to severe wind gusts. These are also needed by the wind energy industry for the planning, design, and operation of wind turbines.

2) Lightning strikes can cause significant disruption to electricity infrastructure, and the potential for more accurate lightning predictions from convection-permitting climate models is likely to be of considerable interest to utility companies.

Multimodel ensemble experiments such as ENSEMBLES (Hewitt and Griggs 2004), NARCCAP (Mearns et al. 2009), NARCliM (Evans et al. 2014), and CORDEX (Giorgi et al. 2009) are limited by the inherent deficiencies in traditional convectionparameterized models. Although they provide valuable information about uncertainties in projections of seasonal mean rainfall and dynamically driven frontal systems, they cannot provide reliable estimates of changes in summertime rainfall intensity and duration or other convectively driven phenomena such as severe wind gusts. For this, explicit representation of convective storms, only possible in convectionpermitting models, is crucial. However, currently only single-model realizations over small domains are available at these resolutions. There is a need for an international effort, for example, CORDEX, to provide coordinated multimodel experiments at convection-permitting resolutions over a series of

TABLE I. Summary of currently available future climate projections and new information from highresolution climate modeling, for selected impact areas.

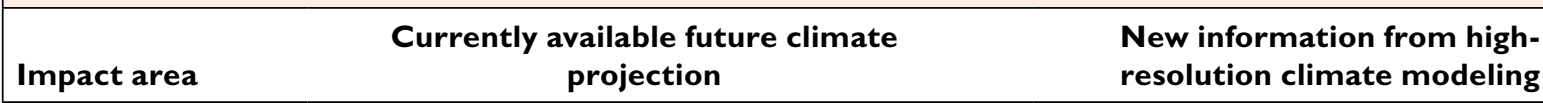

Flash flooding Heavy daily rainfall is expected to increase globally, (important in urban with projected increases across northern Europe and areas and small steep the United Kingdom in winter. Coarse-resolution catchments) climate models are unable to provide reliable projections of future changes in short-duration, intense rainfall.

Renewable energy (wind energy)

\begin{tabular}{l}
\hline Transport (flood- \\
ing, visibility, strong \\
winds, and snow)
\end{tabular}

Future changes in wind are uncertain; $12-25-\mathrm{km}$ resolution models with appropriate gust diagnostics can represent cyclonic storms and their associated winds, but not the most severe convective wind gusts.

Heavy daily rainfall is expected to increase (depending on region and season) with an associated increase in large-scale flooding, but see above for flash flooding. There is large uncertainty in fog projections at $25 \mathrm{~km}$. Coarse-resolution models should be sufficient for projecting changes in cyclonic storms and temperature-driven changes in snow.

Electrical distribution (lightning)
The 25-km models suggest increases in the number of lightning days in the future across the United Kingdom, but there is considerable uncertainty in the accuracy of coarse model lightning diagnostics.
First evidence that intense rainfall events, associated with severe flash flooding ( $30 \mathrm{~mm}$ in an hour), could become several times more frequent by the end of the century (Kendon et al. 2014).

Kilometer-scale models are needed to represent severe wind gusts, associated with convective squall lines.

See above for flash flooding. High-resolution models are needed to adequately represent severe wind gusts and convective snow storms. High resolutions may be required for accurate projections of local fog and snow over mountains.

New lightning diagnostics, developed for kilometer-scale models, have the potential for more accurate lightning predictions. 
common domains to estimate modeling uncertainty at these scales. This would allow a comprehensive evaluation of the potential for improving simulations of not only precipitation characteristics, but other aspects of climate such as land-atmosphere interactions, convective systems, and mountain or urban effects that are impacted by the improved representation of surface heterogeneities.

In the United Kingdom, an update to the UKCP09 projections is currently underway. This will include a downscaling component, running an ensemble of kilometer-scale models over the United Kingdom. This will hopefully allow projections to be provided on subdaily and local scales, with some estimate of uncertainty, which was beyond the UKCP09 modeling capability. We note, however, that the very high cost of convection-permitting simulations means it is not possible to run simulations at these scales for many regions and for large ensembles of driving data. This impacts our ability to fully explore uncertainties at these scales. This is of critical importance for climate change projections, which are necessarily probabilistic and need to incorporate uncertainty due to natural climate variability as well as modeling uncertainty. A potential approach for future progress could be through combined statistical and dynamical downscaling. For example, it may be possible to subselect periods and ensemble members for dynamical downscaling from the large-scale conditions and thus achieve effective targeting of kilometer-scale simulations. In particular, early work suggests statistical regression relationships based on the large-scale climate state may be skillful in identifying when local precipitation extremes may occur (although not their intensity or duration) and hence when information from a convection-permitting model is needed. It should be noted that although the signal coming from the convection-permitting model is conditional on the larger-scale environment, it still provides a considerable improvement in local projections compared to solely relying on coarser resolutions.

Despite the advent of kilometer-scale regional climate models, our confidence in projections is strongly controlled by the ability of global climate models to represent relevant large-scale processes and changes in large-scale circulation patterns. In parallel with developments in convection-permitting regional climate modeling, there are now a number of examples of high-resolution experiments with global climate models. Long climate experiments have been performed within the United Kingdom on the Partnership for Advanced Computing in Europe (PRACE): Weather-Resolving Simulations of Climate for Global
Environmental Risk (UPSCALE) project (Mizielinski et al. 2014) with GCMs at $25-\mathrm{km}$ grid spacing. At resolutions of $60 \mathrm{~km}$ or higher, large-scale moisture transport seems to have converged in the midlatitudes (Demory et al. 2014). The representation of many other processes is also found to improve with increasing model resolution-for example, atmospheric blocking (Scaife et al. 2011; Berckmans et al. 2013) and regional modes of variability (MacLachlan et al. 2014); however, the convergence of these processes with model resolution is not yet robustly established. The two simulations examined here used very different resolution-driving GCMs. The Alps simulations showed significant biases in large-scale conditions inherited from a $\sim 200-\mathrm{km}$ resolution GCM. These were found to impact rainfall frequency and intensity over Switzerland in downscaling simulations (Figs. ES1-ES4 in the online supplemental material). By comparison, 60-km GCM-driven downscaling simulations over the United Kingdom gave comparable biases to ERA-Interim-driven simulations (Figs. ES5-ES8 in the online supplemental material), suggesting that the $60-\mathrm{km} \mathrm{GCM}$ is able to capture the synoptic and mesoscale variability important for constraining local rainfall in this region. In general, present-day biases will only be a good guide of the reliability of future projections, where the biases relate to the same processes that are controlling the future change. It is essential that GCM ability to capture the key large-scale processes driving future changes, which will vary between regions, is established before any regional downscaling is attempted.

This study is not a comprehensive assessment of the reliability of regional projections from coarseresolution models. It only gives an indication of the robustness of projections going from coarser to higher resolution, and in particular to convectionpermitting scales. The experiments available to date are limited to single-model realizations for different midlatitude regions, and so no estimate of modeling uncertainty in the climate change signal is possible. There are also many other potential deficiencies, in some cases relating to limitations that are common to all current climate models. For example, there are large uncertainties in Earth system processes that impact atmospheric $\mathrm{CO}_{2}$ concentrations for given $\mathrm{CO}_{2}$ emissions as well as provide feedbacks on climate change, and uncertainties exist in processes occurring on very small scales, such as cloud microphysics. One important question is the extent to which we may expect changes to be robust on going to even higher resolutions. In the foreseeable future, it will likely become possible to run climate simulations at 
convection-resolving scales (grid scales on the order of $10 \mathrm{~m}$ ) for very small domains. Initial indications from numerical weather prediction are that the representation of convection does not necessarily improve with further increases in resolution once in the regime of being able to explicitly represent convection (Hanley et al. 2015), given our current knowledge about the representation of turbulence and microphysical processes. However, what we can say is that even at kilometer-scale resolution, these models generate new climate projections with potentially profound implications for a number of sectors.

ACKNOWLEDGMENTS. E.J. Kendon and M.J. Roberts gratefully acknowledge funding from the Joint Department of Energy and Climate Change (DECC) and Department for Environment Food and Rural Affairs (Defra) Met Office Hadley Centre Climate Programme (GA01101). This work also forms part of a joint U.K. Met Office and Natural Environment Research Council (UKMO-NERC) funded project on Convective Extremes (CONVEX, NE/1006680/1) and the European Research Council funded INTENSE project (ERC-2013-CoG). N. Ban is funded by the Swiss National Science Foundation through Grant 200021_132614 and through the Sinergia Grant CRSII2_154486 crCLIM. H.J. Fowler is funded by the Wolfson Foundation and the Royal Society as a Royal Society Wolfson Research Merit Award (WM140025) holder. G. Fosser acknowledges funding from the French National Research Agency (ANR) within the project REMEMBER (contract ANR-12-SENV-001). J.P. Evans is funded through the Australian Research Council as part of the Future Fellowship FT110100576.

\section{REFERENCES}

Argueso, D., J. P. Evans, L. Fita, and K. J. Bormann, 2014: Temperature response to future urbanization and climate change. Climate Dyn., 42, 2183-2199, doi:10.1007/s00382-013-1789-6.

— - _ - A. J. Pitman, and A. Di Luca, 2015: Effects of city expansion on heat stress under climate change conditions. PLoS One, 10, e0117066, doi:10.1371 /journal.pone.0117066.

Ban, N., J. Schmidli, and C. Schar, 2014: Evaluation of the convection-resolving regional climate modeling approach in decade-long simulations. J. Geophys. Res. Atmos., 119, 7889-7907, doi:10.1002/2014JD021478.

,$- \ldots$, and —_, 2015: Heavy precipitation in a changing climate: Does short-term summer precipitation increase faster? Geophys. Res. Lett., 42, 1165-1172, doi:10.1002/2014GL062588.
Berckmans, J., T. Woollings, M.-E. Demory, P.-L. Vidale, and M. J. Roberts, 2013: Atmospheric blocking in a high resolution climate model: Influences of mean state, orography and eddy forcing. Atmos. Sci. Lett., 14, 34-40, doi:10.1002/asl2.412.

Browning, K. A., 2004: The sting at the end of the tail: Damaging winds associated with extratropical cyclones. Quart. J. Roy. Meteor. Soc., 130, 375-399, doi:10.1256/qj.02.143.

CH2011, 2011: Swiss climate change scenarios CH2011. C2SM/MeteoSwiss/ETH/NCCR Climate/OcCC, 88 pp. [Available online at http://ch2011.ch/.]

Chan, S. C., E. J. Kendon, H. J. Fowler, S. Blenkinsop, C. A. T. Ferro, and D. B. Stephenson, 2013: Does increasing the spatial resolution of a regional climate model improve the simulated daily precipitation? Climate Dyn., 41, 1475-1495, doi:10.1007/s00382 -012-1568-9.

,,,,----- , and C. A. T. Ferro, 2014a: The value of high-resolution Met Office regional climate models in the simulation of multi-hourly precipitation extremes. J. Climate, 27, 6155-6174, doi:10.1175/JCLI-D-13-00723.1.

,,,---- , and N. M. Roberts, 2014b: Projected increases in summer and winter UK subdaily precipitation extremes from high resolution regional climate models. Environ. Res. Lett., 9, 084019, doi:10.1088/1748-9326/9/8/084019.

Dai, A., 2006: Precipitation characteristics in eighteen coupled climate models. J. Climate, 19, 4605-4630, doi:10.1175/JCLI3884.1.

Dale, M., B. Luck, H. J. Fowler, S. Blenkinsop, E. Gill, J. Bennett, E. J. Kendon, and S. C. Chan, 2016: New climate change rainfall estimates for sustainable drainage. Proc. Inst. Civ. Eng.: Eng. Sustainability, doi:10.1680/jensu.15.00030, in press.

Dee, D. P., and Coauthors, 2011: The ERA-Interim reanalysis: Configuration and performance of the data assimilation system. Quart. J. Roy. Meteor. Soc., 137, 553-597, doi:10.1002/qj.828.

Demory, M.-E., P. L. Vidale, M. Roberts, P. Berrisford, J. Strachan, R. Schiemann, and M. Mizielinski, 2014: The role of horizontal resolution in simulating drivers of the global hydrological cycle. Climate Dyn., 42, 2201-2225, doi:10.1007/s00382-013-1924-4.

Done, J., C. A. Davis, and M. L. Weisman, 2004: The next generation of NWP: Explicit forecasts of convection using the weather research and forecasting (WRF) model. Atmos. Sci. Lett., 5, 110-117, doi:10.1002/asl.72.

Evans, J. P., F. Ji, C. Lee, P. Smith, D. Argueso, and L. Fita, 2014: Design of a regional climate modelling projection ensemble experiment-NARCliM. Geosci. Model Dev., 7, 621-629, doi:10.5194/gmd-7-621-2014. 
Fosser, G., S. Khodayar, and P. Berg, 2015: Benefit of convection permitting climate model simulations in the representation of convective precipitation. Climate Dyn., 44, 45-60, doi:10.1007/s00382-014-2242-1.

,-- , and -2016 : Climate change in the next 30 years: what can a convection-permitting model tell us that we did not already know? Climate Dyn., doi:10.1007/s00382-016-3186-4, in press.

Gensini, V. A., and T. L. Mote, 2014: Estimations of hazardous convective weather in the United States using dynamical downscaling. J. Climate, 27, 6581-6589, doi:10.1175/JCLI-D-13-00777.1.

Giorgi, F., C. Jones, and G. R. Asrar, 2009: Addressing climate information needs at the regional level: the CORDEX framework. WMO Bull., 58 (3), 175-183.

Golding, B. W., 1998: Nimrod: A system for generating automated very short range forecasts. Meteor. Appl., 5, 1-16, doi:10.1017/S1350482798000577.

Hand, W. H., and G. Cappelluti, 2011: A global hail climatology using the UK Met Office convection diagnosis procedure (CDP) and model analyses. Meteor. Appl., 18, 446-458, doi:10.1002/met.236.

Hanley, K. E., R. S. Plant, T. H. M. Stein, R. J. Hogan, J. C. Nicol, H. W. Lean, C. Halliwell, and P. A. Clark, 2015: Mixing length controls on high resolution simulations of convective storms. Quart. J. Roy. Meteor. Soc., 141, 272-284, doi:10.1002/qj.2356.

Hewitt, C. D., and D. J. Griggs, 2004: Ensemblesbased predictions of climate changes and their impacts. Eos, Trans. Amer. Geophys. Union, 85, 566, doi:10.1029/2004EO520005.

Hohenegger, C., P. Brockhaus, and C. Schär, 2008: Towards climate simulations at cloud-resolving scales. Meteor. Z., 17, 383-394, doi:10.1127/0941-2948/2008/0303.

,,-- C. S. Bretherton, and C. Schär, 2009: The soil moisture-precipitation feedback in simulations with explicit and parameterized convection. J. Climate, 22, 5003-5020, doi:10.1175/2009JCLI2604.1.

Kendon, E. J., N. M. Roberts, C. A. Senior, and M. J. Roberts, 2012: Realism of rainfall in a very high resolution regional climate model. J. Climate, $\mathbf{2 5}$, 5791-5806, doi:10.1175/JCLI-D-11-00562.1.

,-- H. J. Fowler, M. J. Roberts, S. C. Chan, and C. A. Senior, 2014: Heavier summer downpours with climate change revealed by weather forecast resolution model. Nat. Climate Change, 4, 570-576, doi:10.1038/nclimate2258.

Klein Tank, A., J. Beersma, J. Bessembinder, B. Van den Hurk, and G. Lenderink, 2015: KNMI'14 climate scenarios for the Netherlands: A guide for professionals in climate adaptation. KNMI, 34 pp. [Available online at http://projects.knmi.nl/publications /showAbstract.php?id=10756.]
Knote, C., G. Heinemann, and B. Rockel, 2010: Changes in weather extremes: Assessment of return values using high resolution climate simulations at convection-resolving scale. Meteor. Z., 19, 11-23, doi:10.1127/0941-2948/2010/0424.

Lean, H. W., P. A. Clark, M. Dixon, N. M. Roberts, A. Fitch, R. Forbes, and C. Halliwell, 2008: Characteristics of high-resolution versions of the Met Office Unified Model for forecasting convection over the United Kingdom. Mon. Wea. Rev., 136, 3408-3424, doi:10.1175/2008MWR2332.1.

Lenderink, G., and E. van Meijgaard, 2008: Increase in hourly precipitation extremes beyond expectations from temperature changes. Nat. Geosci., 1, 511-514, doi:10.1038/ngeo262.

MacLachlan, C., and Coauthors, 2014: Global Seasonal forecast system version 5 (GloSea5): A high-resolution seasonal forecast system. Quart. J. Roy. Meteor. Soc., 141, 1072-1084. doi:10.1002/qj.2396.

Mahoney, K., M. A. Alexander, G. Thompson, J. J. Barsugli, and J. D. Scott, 2012: Changes in hail and flood risk in high-resolution simulations over Colorado's mountains. Nat. Climate Change, 2, 125-131, doi:10.1038/nclimate1344.

McCaul, E. W., S. J. Goodman, K. M. LaCasse, and D. J. Cecil, 2009: Forecasting lightning threat using cloudresolving model simulations. Wea. Forecasting, 24, 709-729, doi:10.1175/2008WAF2222152.1.

Mearns, L. O., W. J. Gutowski, R. Jones, L.-Y. Leung, S. McGinnis, A. M. B. Nunes, and Y. Qian, 2009: A regional climate change assessment program for North America. Eos, Trans. Amer. Geophys. Union, 90, 311-312, doi:10.1029/2009EO360002.

Melillo, J. M., T. C. Richmond, and G. W. Yohe, Eds., 2014: Climate change impacts in the United States: The Third National Climate Assessment. U.S. Global Change Research Program, 841 pp., doi:10.7930 /J0Z31WJ2.

Mizielinski, M. S., and Coauthors, 2014: High-resolution global climate modelling: The UPSCALE project, a large simulation campaign. Geosci. Model Dev., 7, 1629-1640, doi:10.5194/gmd-7-1629-2014.

Murphy, J. M., and Coauthors, 2009: UK climate projections science report: Climate change projections. Met Office Hadley Centre, 10 pp. [Available online at http:/ukclimateprojections.metoffice.gov.uk/media .jsp? mediaid $=87893$.]

Pan, L.-L., S.-H. Chen, D. Cayan, M.-Y. Lin, Q. Hart, M.-H. Zhang, Y. Liu, and J. Wang, 2011: Influences of climate change on California and Nevada regions revealed by a high-resolution dynamical downscaling study. Climate Dyn., 37, 2005-2020, doi:10.1007 /s00382-010-0961-5. 
Prein, A. F., and Coauthors, 2015: A review on regional convection-permitting climate modeling: Demonstrations, prospects and challenges. Rev. Geophys., 53, 323-361, doi:10.1002/2014RG000475.

Price, C., and D. Rind, 1992: A simple lightning parameterization for calculating global lightning distributions. J. Geophys. Res., 97, 9919-9933, doi:10.1029/92JD00719.

Rasmussen, R., and Coauthors, 2014: Climate change impacts on the water balance of the Colorado headwaters: High-resolution regional climate model simulations. J. Hydrometeor., 15, 1091-1116, doi:10.1175 /JHM-D-13-0118.1.

Scaife, A. A., and Coauthors, 2011: Improved Atlantic winter blocking in a climate model. Geophys. Res. Lett., 38, L23703, doi:10.1029/2011GL049573.

Schwartz, C. S., 2014: Reproducing the September 2013 record-breaking rainfall over the Colorado Front Range with high-resolution WRF forecasts. Wea. Forecasting, 29, 393-402, doi:10.1175/WAF -D-13-00136.1.

Stephens, G. L., and Coauthors, 2010: Dreary state of precipitation in global models. J. Geophys. Res., 115, D24211, doi:10.1029/2010JD014532.

Stevens, B., and Coauthors, 2013: Atmospheric component of the MPI-M Earth System Model: ECHAM6. J. Adv. Model. Earth Syst., 5, 146-172, doi:10.1002 /jame.20015.

Tolle, M. H., O. Gutjahr, G. Busch, and J. C. Thiele, 2014: Increasing bioenergy production on arable land: Does the regional and local climate respond? Germany as a case study. J. Geophys. Res. Atmos., 119, 2711-2724, doi:10.1002/2013JD020877.
Trapp, R. J., E. D. Robinson, M. E. Baldwin, N. S. Diffenbaugh, and B. R. J. Schwedler, 2011: Regional climate of hazardous convective weather through high-resolution dynamical downscaling. Climate Dyn., 37, 677-688, doi:10.1007/s00382-010-0826-y.

Trusilova, K., B. Fruh, S. Brienen, A. Walter, V. Masson, G. Pigeon, and P. Becker, 2013: Implementation of an urban parameterization scheme into the Regional Climate Model COSMO-CLM. J. Appl. Meteor. Climatol., 52, 2296-2311, doi:10.1175/JAMC -D-12-0209.1.

Walters, D. N., and Coauthors, 2011: The Met Office Unified Model global atmosphere 3.0/3.1 and JULES global land 3.0/3.1 configurations. Geosci. Model Dev., 4, 919-941, doi:10.5194/gmd-4-919-2011.

Weisman, M. L., C. Davis, W. Wang, K. W. Manning, and J. B. Klemp, 2008: Experiences with 0-36-h explicit convective forecasts with the WRF-ARW model. Wea. Forecasting, 23, 407-437, doi:10.1175 /2007WAF2007005.1.

Weusthoff, T., F. Ament, M. Arpagaus, and M. W. Rotach, 2010: Assessing the benefits of convectionpermitting models by neighborhood verification: Examples from MAP D-PHASE. Mon. Wea. Rev., 138, 3418-3433, doi:10.1175/2010MWR3380.1.

Wilkinson, J. M., and F. J. Bornemann, 2014: A lightning forecast for the London 2012 Olympics opening ceremony. Weather, 69, 16-19, doi:10.1002/wea.2176.

Wuest, M., C. Frei, A. Altenhoff, M. Hagen, M. Litschi, and C. Schär, 2010: A gridded hourly precipitation dataset for Switzerland using rain-gauge analysis and radar-based disaggregation. Int. J. Climatol., 30, 1764-1775, doi:10.1002/joc.2025. 
AMS titles now

available as eBooks

at springer.com

\section{AMS BOOKS}

\section{RESEARCH APPLICATIONS HISTORY}

www.ametsoc.org/amsbookstore

黛 Springer

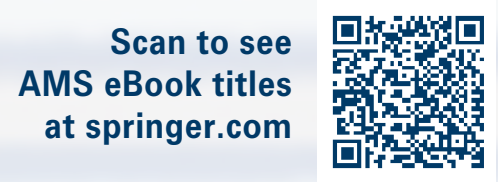

Springer

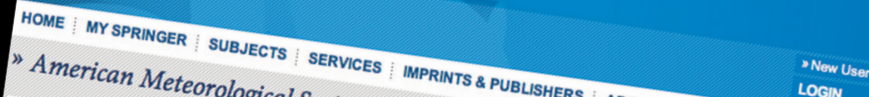

"American Meteorological SOCiety
"AOMTIN

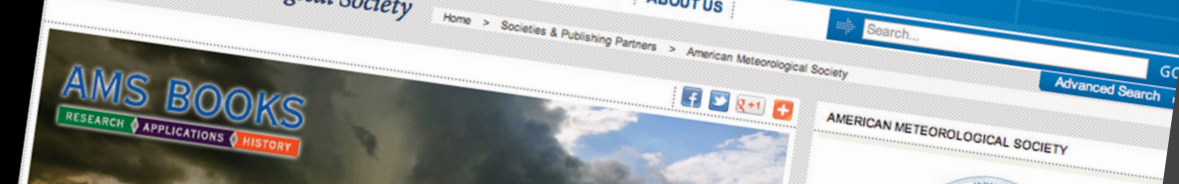

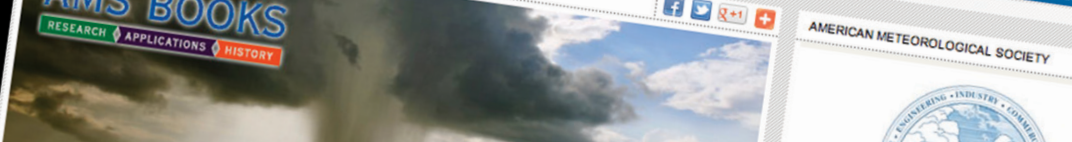

American

Promoting the dewerogical Society

the atmos the deverap

the atmospheric and relont and disseminatb of

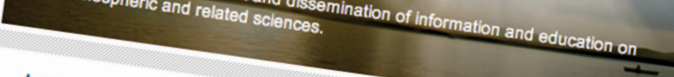

American Meteorological Society eB

AMS Books

published by the AMs a monograph publishing pron

shing program related to he peer-

sos a series related to the peer-entewed

related to tha as eBooks) as weil ar ariy out-ortprint vol metoorological and historica journals

to the atmospheric sciences a growing list of academis, which have been urough ographs

ing policy, and general-interest books

Sort listing by:

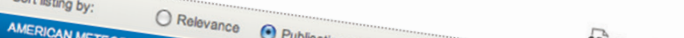

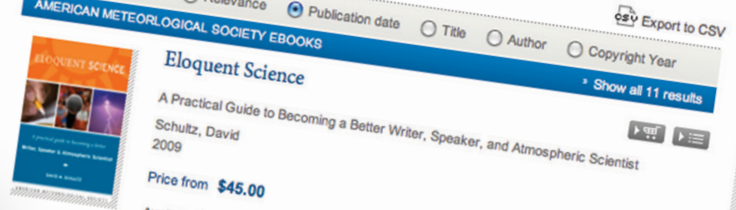

$\$ 45.00$

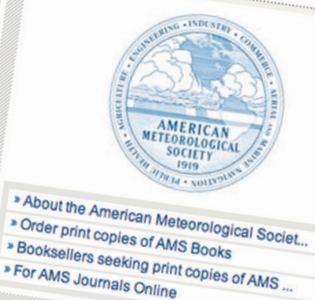

